\title{
PERBEDAAN PEMAHAMAN KONSEP FISIKA ANTARA MODEL PEMBELAJARAN BERBASIS PROYEK DENGAN MODEL PEMBELAJARAN LANGSUNG PADA SISWA KELAS VIII SMP NEGERI 14 PALU
}

\author{
Nur Azizah, Syamsu dan Yusuf Kendek \\ e-mail: nurazizahs719@gmail.com \\ Program Studi Pendidikan Fisika FKIP Universitas Tadulako \\ Jl. Soekarno Hatta Km. 9 Kampus Bumi Tadulako Tondo Palu - Sulawesi Tengah
}

\begin{abstract}
Abstrak - Penelitian ini bertujuan untuk mengetahui ada tidaknya perbedaan pemahaman konsep fisika siswa pada materi gaya dan penerapannya, yang diajarkan dengan menggunakan model pembelajaran berbasis proyek dan model pembelajaran langsung pada siswa kelas VIII SMP Negeri 14 Palu. Jenis penelitian yang digunakan adalah kuasi eksperimen dengan desain "The non equivalen pretest-posttest design" Populasi penelitian ini adalah seluruh siswa kelas VIII SMP Negeri 14 Palu. Sampel dipilih dengan menggunakan teknik purposive sampling dan menghasilkan kelas VIII B4 sebagai kelas eksperimen dan kelas VIII A1 sebagai kelas kontrol. Instrumen yang digunakan berupa tes pemahaman konsep siswa dalam bentuk pilihan ganda. Berdasarkan hasil pengolahan data dari 25 skor ideal, diperoleh rerata skor tes awal pemahaman konsep siswa kelas eksperimen adalah 6,83 dan untuk tes akhir adalah 16,17. Untuk kelas kontrol diperoleh rerata skor tes awal 5,93 sedangkan untuk tes akhir adalah 9,3. Analisis data tes dilakukan dengan teknik statistik uji-t dua pihak untuk menguji perbedaan rerata skor pemahaman konsep siswa dengan signifikasi $\alpha=0,05$. Diperoleh nilai Hasil $t_{\text {hitung }}=3,08$ dan $t_{\text {tabel }}=2,00$. Ini berarti bahwa nilai $t_{\text {hitung }}$ berada diluar daerah penerimaan $H_{0}$. Dengan demikian dapat disimpulkan bahwa terdapat perbedaan pemahaman konsep fisika siswa pada materi gaya dan penerapannya antara kelas yang diajarkan dengan menggunakan model pembelajaran berbasis proyek dan kelas yang diajarkan dengan menggunakan model pembelajaran langsung.
\end{abstract}

Kata Kunci : Pembelajaran Berbasis Proyek, Pembelajaran Langsung, Pemahaman Konsep

\section{PENDAHULUAN}

Pembelajaran yang hanya berpusat pada guru umumnya guru mentransfer pengetahuan. Padahal pada hakikatnya belajar sains khususnya fisika bukan hanya mengingat dan memahami konsep-konsep yang telah ditemukan oleh para ilmuwan, tetapi juga bagaimana kita membiasakan bersikap seperti yang dilakukan ilmuwan untuk menemukan konsep-konsep melalui percobaan dan penelitian ilmiah.

Berdasarkan hasil observasi penulis, masalah umumnya yang terjadi di SMP yang ada di kota Palu khususnya di SMP Negeri 14 Palu adalah keterbatasan alat bantu mengajar dan juga pemahaman konsep siswa terutama pada pelajaran fisika masih rendah.

Pemilihan model pembelajaran hendaknya dapat mengatasi permasalahan di atas. Salah satu model pembelajaran yang sesuai adalah model pembelajaran berbasis proyek. Pembelajaran berbasis proyek merupakan model pembelajaran yang memperhatikan pemahaman peserta didik dalam melakukan eksplorasi, penilaian, interpretasi dan mensintesis informasi melalui cara yang bermakna. ${ }^{[1]}$

Pembelajaran berbasis proyek melatih siswa untuk memahami suatu materi secara bermakna dengan caranya sendiri dan melatih peserta didik untuk dapat mengaitkan antara materi yang didapat di kelas dengan fenomena dalam kehidupan nyata. ${ }^{[2]}$ selain itu juga model pembelajaran berbasis proyek dapat meningkatkan kerjasama antara peserta didik karena proyeknya dibuat secara berkelompok. Melalui pembelajaran berbasis proyek ini diharapkan nantinya siswa dapat menghasilkan alat bantu pembelajaran yang sederhana dan dapat membantu proses pembelajaran yang saat ini terkendala pada kurangnya alat praktikum.

Pemahaman konsep saat ini jarang diperhatikan oleh guru, seperti yang terjadi pada SMP Negeri 14 Palu. Guru mengajar semata-mata hanya supaya siswa mendapatkan nilai yang tinggi dan lulus ujian nasional. Padahal pemahaman konsep siswa perlu dikembangkan sejak di bangku SMP agar siswa 
lebih memahami dan mengingat konsep-konsep fisika bukan hanya menghafal rumus-rumus, serta siswa juga dapat mengaitkan antara fenomena yang terjadi dalam kehidupannya dengan ilmu fisika serta dapat menjadi bekal bagi peserta didik saat menuntut ilmu di jenjang yang lebih tinggi.

Menurut Erman Suherman dalam Arcnawa ${ }^{[3]}$ pemahaman konsep berkenaan dengan pengertian yang memadai tentang sesuatu, berbuat lebih daripada mengingat, dapat menangkap suatu makna, dan menjelaskan makna atau ide pokok dengan menggunakan yang telah dipahami sebelumnya.

Mengingat bahwa masing-masing peserta didik memiliki gaya belajar yang berbeda, maka Pembelajaran Berbasis Proyek memberikan kesempatan kepada para peserta didik untuk menggali konten (materi) dengan menggunakan berbagai cara yang bermakna bagi dirinya, dan melakukan eksperimen secara kolaboratif. Pembelajaran Berbasis Proyek merupakan investigasi mendalam tentang sebuah topik dunia nyata, hal ini akan berharga bagi atensi dan usaha peserta didik. ${ }^{[4]}$

Berdasarkan penelitian yang dilakukan $\mathrm{Ni}$ Luh Putu Mery Marlinda. ${ }^{[5]}$ bahwa dengan pembelajaran berbasis proyek terdapat perbedaan kinerja ilmiah dan kemampuan berpikir kreatif. Hal yang serupa juga diharapkan agar model pembelajaran berbasis proyek ini juga dapat meningkatkan pemahaman konsep siswa SMP.

\section{METODE PENELITIAN}

Jenis penelitian yang digunakan pada penelitian kali ini dilihat dari teknik yang digunakan adalah penelitian kuasi eksperimen.

Adapun desain penelitian yang digunakan yaitu the non ekivalen pretest-posttest design. Desain penelitian yang digunakan dapat dilukiskan seperti pada Tabel 1.

Tabel 1 : The non ekivalen pretest-posttest design

\begin{tabular}{lccc}
\hline Kelompok & Prates & Perlakuan & Pascates \\
\hline Eksperimen & $\mathrm{O}_{1}$ & $\mathrm{X}$ & $\mathrm{O}_{2}$ \\
Kontrol & $\mathrm{O}_{1}$ & - & $\mathrm{O}_{2}$ \\
\hline
\end{tabular}

Keterangan:

$X$ : Perlakuan dengan model pembelajaran berbasis proyek

o : -
Penelitian dilakukan di SMP Negeri 14 Palu. Penelitian dilaksanakan pada bulan September-Oktober 2015. Populasi dalam penelitian ini adalah seluruh siswa kelas VIII SMP Negeri 14 Palu tahun pelajaran 2015/2016 yang terdiri dari 7 kelas. Sampel dalam penelitian ini adalah kelas VIII B4 dan VIII A1. Teknik pengumpulan sampel yang digunakan adalah purposive sampling, yaitu teknik penentuan sampel dengan pertimbangan tertentu.

\section{HASIL DAN PEMBAHASAN}

\subsection{Hasil Penelitian}

\subsubsection{Deskripsi Pemahaman konsep Siswa}

Data pemahaman konsep fisika siswa diperoleh dari hasil pretest dan posttest yang dilakukan pada kedua kelas tersebut. Adapun data hasil pemahaman konsep fisika siswa dapat dilihat pada tabel berikut :

\begin{tabular}{lllll}
\hline & \multicolumn{2}{l}{ Kelas Kontrol } & \multicolumn{2}{l}{ Kelas Eksperimen } \\
\cline { 2 - 5 } Deskripsi & Pretest & Posttest & Pretest & Posttest \\
Jumlah Siswa & 30 & 30 & 30 & 30 \\
Skor Maksimum & 12 & 15 & 12 & 22 \\
Skor Minimum & 1 & 4 & 2 & 10 \\
Skor Total & 178 & 279 & 205 & 485 \\
Skor Rata-rata & 5,93 & 9,3 & 6,83 & 16,17 \\
Standar Deviasi & 2,89 & 3,09 & 2,97 & 3,03 \\
\hline Tabel 2 Deskripsi skor tes pemahamn konsep siswa kelas \\
eksperimen dan kelas kontrol.
\end{tabular}

Dari tabel 2 dilihat bahwa terdapat perbedaan nilai pada kelas kontrol yang menggunakan model pembelajaran langsung dan model pembelajaran berbasis proyek.

\subsubsection{Uji Normalitas}

Pengujian normalitas data penelitian ini menggunakan Chi-kuadrat dengan kriteria penerimaan $X_{\text {hitung }}^{2}<X^{2}$ tabel, taraf signifikan $\alpha=$ 0,05 , dan derajat kebebasan $\mathrm{dk}=\mathrm{k}-3$. Data yang diuji meliputi tes awal dan tes akhir pemahaman konsep baik kelas eksperimen maupun kelas kontrol. Hasil uji normalitas tes awal dan tes akhir dari kelas eksperimen dan kelas kontrol dapat dilihat pada Tabel 3.

Tabel 3 : Hasil Uji Normalitas Tes Awal dan Tes Akhir Kelas Eksperimen dan Kelas Kontrol

\begin{tabular}{|c|c|c|c|c|}
\hline \multirow[t]{2}{*}{ Uraian } & \multicolumn{2}{|c|}{ Tes Awal } & \multicolumn{2}{|c|}{ Tes Akhir } \\
\hline & Eksperimen & Kontrol & Eksperimen & Kontrol \\
\hline Sampel & 30 & 30 & 30 & 30 \\
\hline$x_{\text {Hitung }}^{2}$ & 2,3781 & 2,5234 & 4,6967 & 3,3954 \\
\hline$x_{\text {tabel }}^{2}$ & \multicolumn{2}{|c|}{7,81} & \multicolumn{2}{|l|}{7,81} \\
\hline Ket & \multicolumn{2}{|c|}{ Normal } & \multicolumn{2}{|c|}{ Normal } \\
\hline
\end{tabular}


Berdasarkan uji normalitas pada Tabel 3 dengan menggunakan Chi-kuadrat dengan kriteria penerimaan $x^{2}{ }_{\text {hitung }}<X^{2}{ }_{(1-\alpha)(k-3)}$, dimana untuk tes awal baik kelas eksperimen maupun kelas kontrol nilai $X^{2}$ hitung lebih kecil daripada nilai $X^{2}(1-\alpha)(k-3)$. Begitupula untuk tes akhir, nilai $X^{2}{ }_{\text {hitung }}$ lebih kecil daripada nilai $X^{2}{ }_{1}$ $-a)(k-3)$, baik di kelas eksperimen maupun kelas kontrol. Artinya, data tes awal dan tes akhir baik di kelas eksperimen maupun kelas kontrol terdistribusi normal.

\subsubsection{Uji Homogenitas}

Pengujian

homogenitas data menggunakan uji-F dengan kriteria jika $F_{\text {hitung }}$ $<F_{\text {tabel }}$ maka data homogen. Hasil uji homogenitas dari kelas eksperimen dan kelas kontrol dapat dilihat pada Tabel 4.

Tabel 4. Hasil Uji Homogenitas Tes Awal dan Tes Akhir

\begin{tabular}{lccc}
\hline Uraian & Tes awal & Tes Akhir & Ket \\
\hline $\mathbf{F}_{\text {hitung }}$ & 0,75 & 1,21 & Homogen \\
$\mathbf{F}_{\text {tabel }}$ & 1,77 & 1,77 & \\
\hline
\end{tabular}

Berdasarkan Tabel 4, nilai $\mathrm{F}_{\text {hitung }}<\mathrm{F}_{\text {tabel }}$. Hal ini menunjukkan bahwa data tersebut memiliki varians yang sama (homogen).

\section{Uji Hipotesis}

Uji Perbedaan Rata-Rata

Pengujian hipotesis ini menggunakan statistik parametrik uji-t (uji dua pihak). Data hasil pengujian statistik tes awal dan tes akhir dapat dilihat pada Tabel 5 dan Tabel 6.

Tabel 5 : Uji Perbedaan Rata - Rata Kelas Eksperimen dan Kelas Kontrol(pretest)

\begin{tabular}{lcccc}
\multicolumn{1}{c}{ Kelas } & $\overline{\mathbf{X}}$ & $\mathbf{t}_{\text {hitung }}$ & $\begin{array}{c}\mathbf{t}_{\text {tabel }} \\
(\alpha=\mathbf{0 , 0 5})\end{array}$ & Keputusan \\
\hline Eksperimen & 6,77 & 0,32 & 2,00 & $\mathrm{H}_{0}$ diterima \\
Kontrol & 5,93 & & & \\
\hline
\end{tabular}

Tabel 6 : Uji Perbedaan Rata - Rata Kelas Eksperimen dan Kelas Kontrol(posttest)

\begin{tabular}{lcccc}
\hline \multicolumn{1}{c}{ Kelas } & $\overline{\mathbf{X}}$ & $\mathbf{t}_{\text {hitung }}$ & $\begin{array}{c}\mathbf{t}_{\text {tabel }} \\
(\alpha=\mathbf{0 , 0 5})\end{array}$ & Keputusan \\
\hline Eksperimen & 16,55 & 3,08 & 2,00 & $\mathrm{H}_{1}$ diterima \\
Kontrol & 9,68 & & & \\
\hline
\end{tabular}

Berdasarkan Tabel 6 Nilai $t_{\text {hitung }}>t_{\text {tabel }}$ atau $3,08>2,00$. Hal ini menunjukkan bahwa thitung berada diluar daerah penerimaan $\mathrm{H}_{\mathrm{o}}$.

\section{Pembahasan}

Sebelum diberikan treatment, siswa pada kelas eksperimen dan kelas kontrol diberikan tes awal untuk mengetahui kemampuan awal siswa. Selanjutnya, siswa yang berada di kelas eksperimen menerima materi dengan model pembelajaran berbasis proyek, sedangkan siswa pada kelas kontrol menerima materi dengan pembelajaran langsung. Selanjutnya kedua kelas tersebut diberikan tes akhir untuk melihat ada tidaknya perbedaan pemahaman konsep fisika siswa. Tes pemahaman konsep siswa tes akhir sama dengan pada tes awal. Kedua kelas menerima materi dengan cara yang hampir sama yaitu ceramah, hanya saja pada kelas eksperimen mereka membuat model matematik dari apa yang mereka cobakan.

Sesuai dengan yang diungkapkan oleh Stavroula dalam Rahmawati Model pembelajaran berbasis proyek mengajak siswa untuk bekerjasama dalam kelompok. ${ }^{[5]}$ menyatakan pembelajaran berbasis proyek dapat meningkatkan hasil belajar siswa serta kemampuan bekerjasama siswa, karena siswa diberikan kesempatan untuk mengembangkan ide dan belajar untuk mencari solusi dari masalah nyata.

Berdasarkan hasil deskripsi data pemahaman konsep fisika siswa yang sesuai pada tabel 2 diperoleh skor rata-rata dari masing-masing kelas adalah 6,83 dengan standar deviasi adalah 2,97 untuk kelas eksperimen dan 5,93 dengan standar deviasinya adalah 2,89 untuk kelas kontrol. Hasil ini menunjukkan adanya perbedaan yang tidak terlalu signifikan antara kedua kelas, dimana terlihat skor maksimum yang terdapat pada kedua kelas sama yaitu 12 dan skor minimum hanya selisih 1 yaitu 1 untuk kelas kontrol dan 2 untuk kelas eksperimen, dari data tersebut dapat dilihat bahwa pada pretest kemampuan kedua kelas tersebut sama. Sedangkan, untuk kemampuan siswa dari pemberian tes akhir (posttest) diperoleh nilai rata-rata dari masing-masing kelas adalah 16,37 dengan standar deviasinya adalah 3,03 untuk kelas eksperimen dan 9,3 dengan standar deviasinya adalah 3,09 untuk kelas kontrol. Berdasarkan data yang diperoleh tersebut menunjukkan bahwa ada perbedaan yang signifikan antara kedua kelas tersebut, dimana skor maksimum dan minimum yang diperoleh kedua kelas terebut adalah 15 dan 22 untuk kelas kontrol dan eksperimen yaitu selisih 7. 
Hal ini sejalan dengan penelitian yang dilakukan oleh putri rahmawati, bahwa peningkatan penguasaan konsep siswa setelah pembelajaran, pada kelas yang menggunakan model pembelajaran berbasis proyek lebih baik dari kelas yang menggunakan model pembelajaran konvensional ${ }^{[6]}$.

Kemudian dilakukan analisis terhadap uji normalitas serta uji homogenitas varians. Hasilnya baik data tes awal maupun tes akhir keduanya berdistribusi normal, yang berdasrkan pada tabel 3 dengan menggunakan Chi-kuadrat dengan kriteria penerimaan $\chi^{2}$ hitung $<\chi^{2}$ tabel, dimana untuk tes awal baik kelas eksperimen maupun kelas kontrol nilai $\chi^{2}$ hitung lebih kecil daripada nilai $\chi^{2}$ tabel. Dimana nilai $\chi^{2}$ hitung untuk kelas eksperimen adalah $2,38<$ 7,81 dan untuk kelas kontrol 2,52<7,81. Sesuai kriteria pengambilan keputusan, maka baik data dari kelas eksperimen maupun kelas kontrol keduanya berasal dari populasi yang terdiribusi normal. Pada tes akhir kelas eksperimen maupun kelas kontrol nilai $\chi^{2}$ hitung lebih kecil daripada nilai $\chi^{2}$ tabel. Dimana nilai $\chi^{2}$ hitung untuk kelas eksperimen adalah $4,69<$ 7,81 dan untuk kelas kontrol 3,39<7,81. Sesuai kriteria pengambilan keputusan, maka baik data dari kelas eksperimen maupun kelas kontrol keduanya berasal dari populasi yang terdistribusi normal, serta memiliki varians yang homogen dapat dilihat berdasarkan pada tabel 4 dimana nilai $F_{\text {hitung }}<F_{\text {tabel }}$. Hal ini menunjukkan bahwa data tersebut memiliki varians yang sama (homogen). Berdasarkan analisis kuantitatif data tes akhir diketahui, nilaii rata-rata kelas eksperimen lebih besar dibandingkan dengan nilai rata-rata kelas kontrol. Perbedaan antara rerata skor tes akhir kelas eksperimen dan kelas kontrol menunjukkan adanya perbedaan pada pembelajaran yang diterapkan pada kedua kelas tersebut. Perbedaan yang signifikan terjadi pada kelas eksperimen. Dimana kelas eksperimen menggunakan pembelajaran berbasis proyek sedangkan kelas kontroll menggunakan model pembelajaran langsung.

Hal ini sesuai dengan hasil penelitian yang telah dilakukan oleh Navies Luthvitasari,dkk (2012) menyatakan bahwa model pembelajaran berbasis proyek memberikan pengaruh terhadap peningkatan keterampilan berpikir kritis dan keterampilan berpikir kreatif siswa SMK ${ }^{[7]}$.

Selanjutnya dengan menggunakan ratarata skor dapat dilihat hasil uji hipotesis tes awal dan tes akhir sesuai tabel 4 dan tabel 5 dimana pada masing-masing kelas telah diberi perlakuan, diperoleh nilai $t_{\text {hitung }}=0,32$ untuk tes awal dan nilai $t_{\text {hitung }}=3,08$ untuk tes akhir dan nilai $t_{\text {tabel }}=2,00$. Dengan menggunakan kriteria penerimaan $\mathrm{H}_{0}$ dimana $-\mathrm{t}_{(1-0,5 \mathrm{a})}<\mathrm{t}<\mathrm{t}_{(1-0,5 \mathrm{a})}$, diketahui hipotesis $\mathrm{H}_{0}$ tidak terpenuhi atau ditolak dan hipotesis satu $\left(\mathrm{H}_{1}\right)$ diterima. Sehingga pada tes akhir diperoleh $\mathrm{H}_{1}$ (diterima) Artinya terdapat perbedaan pemahaman konsep fisika antara siswa yang diajarkan dengan menggunakan model pembelajaran berbasis proyek dan siswa yang diajarkan dengan menggunakan model pembelajaran langsung.

\section{KESIMPULAN}

Berdasarkan penelitian dan analisis data dapat disimpulkan, bahwa ada perbedaan pemahaman konsep fisika siswa pada materi gaya dan penerapannya, yang diajarkan dengan menggunakan model pembelajaran berbasis proyek dan model pembelajaran langsung dikelas VIII SMP Negeri 14 Palu. Hal ini dapat dilihat berdasarkan hasil posttest pemahaman konsep siswa skor rata-rata kelas kontrol sebesar 9,77 dengan standar deviasinya adalah 3,09 dan skor rata-rata kelas eksperimen sebesar 16,23 dengan standar deviasinya adalah 3,03 dari skor maksimum 25. Pengujian hipotesis dilakukan dengan menggunakan uji-t dua pihak pada posttest, dimana dengan menggunakan rata-rata skor diperoleh nilai $t_{\text {hitung }}=3,08$ dan $t_{\text {tabel }} 2,00$. Berdasarkan data tersebut, kriteria penerimaan $\mathrm{H}_{\mathrm{o}}$ dimana $\left.-\mathrm{t}_{(1-0,5 \alpha)}<\mathrm{t}<\mathrm{t}_{(1-0,5} \alpha\right)$ tidak terpenuhi, $\mathrm{H}_{\mathrm{o}}$ ditolak dan hipotesis satu $\left(\mathrm{H}_{1}\right)$ diterima pada taraf nyata $5 \%$ dan $\mathrm{dk}=66$.

\section{DAFTAR PUSTAKA}

[1] Bell, B.F. (2005). "Children's Science, Contructivism and Learning in Science". Tersedia pada: http://www.gsn.org/web/ontructivism/whatis.htm [17 Desember 2013]..

[2] Kemendikbud. (2013). Strategi Pembelajaran Berbasis Proyek. Pelatihan Pendampingan Kurikulum 2013. Jakarta: Pusat Pengembangan Tenaga Kependidikan Kemendikbud

[3] Arcnawa.(2008). Pemahaman Konsep.(Online), http//one.indoskripsi.com/2008/09/18/pemahaman konsep.html/,(diakses 26 januari 2016)

[4] Ni Luh putu Mery Marlinda (2012)." Pengaruh Model Pembelajaran Berbasis Proyek Terhadap Kemampuan Berpikir Kreatif dan Kinerja Ilmiah Siswa".

[5] Rahmawati, D. (2011). Pengaruh Model Pembelajaran Berbasis Proyek terhadap Hasil Belajar Fisika Siswa (Studi Quasi Eksperimen di SMPN 48 Jakarta). Skripsi pada Sarjana (S1) Pendidikan pada UIN Syarif Hidayatullah Jakarta. Tidak dipublikasikan

[6] Rahmawati, Putri Maesaroh " Pengaruh Model Pembelajaran Berbasis Proyek Terhadap Hasil Belajar 
Biologi Siswa". Skripsi, (jakarta: UIN Syahid, 2009), h.43.

[7] Luthvitasari, N., Made, N. dan Linuwih, S. (2012). "Implementasi Pembelajaran Fisika Berbasis Proyek Terhadap Keterampilan Berpikir Kritis, Berpikir Kreatif Dan Kemahiran Generik Sains". Journal of Innovative Science Education. 1 (2).

Arcnawa.(2008).PemahamanKonsep.(Online),http://o ne.indoskripsi.com/2008/09/18/pemahaman-

konsep.html/,diakses 5 Maret 2010) 